\title{
ANÁLISE DA COMPREENSÃO DOS LEGISLADORES MUNICIPAIS SOBRE A LEI DE RESPONSABILIDADE FISCAL
}

\author{
ANALYSIS OF MUNICIPAL LEGISLATORS' UNDERSTANDING \\ ON THE FISCAL RESPONSIBILITY LAW
}

Elivelton Soares Matias

Faculdade de Ciências Sociais e Aplicadas de Petrolina, PE, Brasil E-mail: erivelto.matias@gmail.com

Josaias Santana dos Santos
Faculdade de Ciências Sociais e Aplicadas de Petrolina, PE, Brasil
E-mail: josaias@yahoo.com.br

Florisvaldo Cunha Cavalcante Junior Instituto Federal do Sertão Pernambucano,PE, Brasil E-mail: junior.cavalcantte@yahoo.com.br

Paulo Rocha Cavalcante

Centro Universitário Joaquim Nabuco, PE, Brasil E-mail: pcavalcante1977@hotmail.com

Recebido em: 20.04.2020 - Aceito em: 22.07.2020

DOI: http://dx.doi.org/10.5902/2526629243667

RESUMO: O artigo teve como objetivo fazer uma análise sobre a compreensão dos vereadores dos municípios da Região Integrada de Desenvolvimento Econômico (RIDE) do polo Petrolina/PE e Juazeiro/BA a respeito da Lei de Responsabilidade Fiscal (LRF). O estudo se classifica como descritivo-exploratório, com abordagem qualitativa, que compreende a pesquisa documental e a aplicação de questionários nos municípios que fazem parte da RIDE. Como resultado, constatou-se que mais de $50 \%$ dos vereadores se capacitaram sobre o tema e uma parte significativa apresentou baixo conhecimento sobre as determinações da LRF, o que sugere/aponta uma carência/deficiência nos investimentos em qualificações, no que diz respeito à aplicabilidade da lei. Os resultados do estudo denotam que os vereadores possuem conhecimento razoável da LRF, mas reconhecem que existe a necessidade da administração das câmaras municipais incentivar os vereadores, oferecendo-os cursos a respeito da referida lei que proporcione uma atuação assertiva na aplicabilidade da legislatura.

Palavras-chave: Poder Legislativo Municipal; Lei de Responsabilidade; Compreensão dos Vereadores. 
ABSTRACT: The article aimed to make an analysis on the understanding of the Councilors of the municipalities of - Integrated Region of Economic Development (RIDE) of the Petrolina/PE and Juazeiro/BA pole regarding the Fiscal Responsibility Law (LRF). The study is classified as descriptive-exploratory, with a qualitative approach, that includes documentary research and application of questionnaires in the municipalities that are part of RIDE. As a result, it was found that more than $50 \%$ of the councilors were trained on the subject and a significant part had low knowledge about the determinations of the LRF, which suggests / points to a lack / deficiency in investment in qualifications, with regard to applicability of the law. The results of the study, show that, the councilors have reasonable knowledge of the $L R F$, but recognize that there is a need for the administration of the municipal councils to encourage the councilors, offering them courses regarding the referred law which provides an assertive performance in the applicability of the legislature.

Keywords: Municipal Legislative Power; Responsibility Law; Understanding of Councilors.

\section{INTRODUÇÃO}

Para que o desenvolvimento do Brasil seja de maneira responsável, o passo primordial é fazer com que os órgãos públicos sejam administrados da melhor maneira possível, tendo como prioridade o combate à corrupção, fazendo com que o dinheiro público seja bem aplicado e seu destino seja transparente.

Com esse objetivo, no dia 04 de maio de 2000 foi sancionado, pelo Presidente da República, um dos melhores instrumentos de combate à corrupção nos órgãos públicos e no controle de gestão pública já criados no Brasil: a Lei de Responsabilidade Fiscal (LRF) - Lei $\mathrm{n}^{\circ}$ 101, de 04 de maio de 2000. Por clamor popular, ela surgiu para que houvesse mudanças na aplicação dos recursos e no controle dos gastos da máquina pública.

Após a aprovação da lei, o administrador de recursos públicos passa a ter a obrigação de planejar o que irá gastar e fazer o controle desses gastos, verificando se irá ou não arrecadar a receita estimada. Passa a ter também que fazer um equilíbrio entre as receitas e despesas, não podendo gastar mais do que se arrecada. Além disso, ele passa a ter que prestar contas perante a sociedade e trazer, também, punições ao não cumprimento da LRF.

O vereador tem um papel importantíssimo no contexto citado acima, sendo de sua responsabilidade fiscalizar e controlar as contas públicas. A Câmara Municipal foi encarregada pela Constituição da República de acompanhar a execução do orçamento do município e verificar a legalidade e legitimidade dos atos do Poder Executivo, enquanto que é função dos vereadores avaliarem, permanentemente, a gestão e as ações do prefeito. 
Como destaca a Constituição Federal (CF) de 5 de outubro de 1988, no seu Art. 31, a fiscalização do município será exercida pelo Poder Legislativo Municipal, mediante controle externo, e pelos sistemas de controle interno do Poder Executivo Municipal, na forma da lei.

A Região Administrativa Integrada de Desenvolvimento (RIDE) do polo Petrolina/PE e Juazeiro/BA foi criada pela Lei Complementar $n^{\circ} 113$, de 19 de setembro de 2001, e regulamentada pelo Decreto $n^{\circ}$ 4.366, de 9 de setembro de 2002.

A RIDE tem como objetivo articular e harmonizar as ações administrativas da União, dos Estados e dos Municípios para a promoção de projetos que visem à dinamização econômica e à provisão de infraestruturas necessárias ao desenvolvimento em escala regional.

Enquanto institucionalidade legalmente constituída, a RIDE tem prioridade no recebimento de recursos públicos destinados a investimentos que estejam de acordo com os interesses consensuados entre os entes. Esses recursos devem contemplar demandas por equipamentos e por serviços públicos, fomentar arranjos produtivos locais, propiciar o ordenamento territorial e, assim, promover o seu desenvolvimento integrado. A Região Administrativa é constituída pelos municípios de Lagoa Grande, Orocó, Petrolina, Santa Maria da Boa Vista, no Estado de Pernambuco, e pelos municípios de Casa Nova, Curaçá, Juazeiro e Sobradinho, no Estado da Bahia.

O estudo se justifica pela necessidade de difusão do tema, em decorrência dos princípios da Lei da Responsabilidade Fiscal, e das atribuições legislativas imprescindíveis que o vereador tem para o cumprimento da mesma. Neste contexto, surge a problemática a qual essa pesquisa busca responder: Qual a compreensão dos vereadores da RIDE polo Petrolina-Juazeiro acerca da LRF quanto ao cumprimento à eficiência e à eficácia?

A relevância desse estudo reside na importância de disseminar os benefícios do conhecimento da Lei de Responsabilidade Fiscal por parte dos vereadores, pois essa legislação aborda muitos pontos cruciais que merecem atenção especial por parte deles. Vale ressaltar, ainda, que não foram encontrados artigos semelhantes, abordando a LRF de forma geral, até a conclusão desse estudo. Diante do exposto, o objetivo da pesquisa foi fazer uma análise sobre a compreensão dos vereadores dos municípios da RIDE - Região Integrada de Desenvolvimento Econômico do polo Petrolina/PE e Juazeiro/BA a respeito da Lei de Responsabilidade Fiscal.

Para melhor cumprir os objetivos propostos, o trabalho foi organizado da seguinte forma: na primeira seção, introdutória, traçou-se um panorama sobre a temática e os objetivos almejados com o estudo; a segunda seção contempla o referencial teórico que trará as subseções denominadas de o Estado na administração pública e suas funções, o orçamento público e a responsabilidade fiscal; a terceira seção traz a metodologia aplicada para o cumprimento dos objetivos do trabalho; enquanto a quarta seção traz a análise e os resultados; e a quinta traz as considerações finais, abordando os resultados do trabalho. 


\section{FUNDAMENTAÇÃO TEÓRICA}

\subsection{O Estado}

\subsubsection{A Administração Pública e suas Funções}

A Administração Pública é um instrumento que auxilia no cumprimento dos objetivos de cuidar do bem-estar e do interesse comum. Silva (2012) compreende a Administração Pública como sendo um conjunto das organizações que assumem a função administrativa, não somente no Poder Executivo, em que ela é predominante, mas, também, nos poderes Legislativos e Judiciários. Diante disso, Correio (2019) ressalta que "a partir da Constituição Federal de 1988 os cidadãos brasileiros passaram a ter direitos inéditos, entre eles, o de exercer o controle sobre a administração pública".

A seguir, no Quadro 1 será exposto as funções de cada poder:

Quadro 1 - Funções Administrativas do Legislativo, Executivo e Judiciário.

\begin{tabular}{|c|c|c|}
\hline Órgão & Função Típica & Função Atípica \\
\hline \multirow[b]{2}{*}{ Legislativo } & \multirow{2}{*}{$\begin{array}{c}\text { Legislar. } \\
\text { Fiscalização } \\
\text { contábil, } \\
\text { financeira, } \\
\text { orçamentária e } \\
\text { patrimonial, do } \\
\text { executivo. } \\
\end{array}$} & $\begin{array}{l}\text { Natureza executiva: ao dispor sobre sua organização, } \\
\text { provendo cargos, concedendo férias, licenças a servidores, etc. }\end{array}$ \\
\hline & & $\begin{array}{l}\text { Natureza jurisdicional: o Senado julga o Presidente da } \\
\text { República nos crimes de responsabilidade. }\end{array}$ \\
\hline \multirow{2}{*}{ Executivo } & \multirow{2}{*}{$\begin{array}{c}\text { Governar e } \\
\text { administrar o } \\
\text { interesse coletivo }\end{array}$} & $\begin{array}{l}\text { Natureza legislativa: o Presidente da República, por exemplo, } \\
\text { adota medida provisória, com força de lei. }\end{array}$ \\
\hline & & $\begin{array}{c}\text { Natureza jurisdicional: o Executivo julga, apreciando defesas } \\
\text { e recursos administrativos. }\end{array}$ \\
\hline \multirow[b]{2}{*}{ Judiciário } & \multirow{2}{*}{$\begin{array}{l}\text { Julgar (função } \\
\text { jurisdicional) }\end{array}$} & Natureza legislativa: regimento interno de seus Tribunais. \\
\hline & & $\begin{array}{l}\text { Natureza executiva: administra ao conceder licenças e férias } \\
\text { aos magistrados e serventuários. }\end{array}$ \\
\hline
\end{tabular}

Fonte: Adaptado da Constituição Federal (Brasil,1988)

O Quadro 1 evidencia que a função de aprovar e de fiscalizar a execução das leis orçamentárias é de competência do Legislativo, enquanto que o Executivo governa e o Judiciário julga. A CGU (2011, p. 12) enfatiza que, "no entanto, nenhum desses poderes é soberano. Isto porque o poder popular é uno e indivisível. O povo, único titular legítimo do Estado, apenas atribui competências para cada poder, que devem ser exercidas com eficiência e dentro dos parâmetros ético-jurídicos".

Vale ressaltar, ainda, que o setor público possui suas especificidades, e entre elas está o estereótipo da ineficiência. Por muito tempo, as organizações públicas foram vistas como ineficientes em virtude de seu aparato burocrático e baixo engajamento de seus dirigentes e servidores com o propósito maior dessas organizações: a prestação de serviço ao público (Freiras \& Pedreneiras, 2020). 
Nesse contexto, cabe ao campo da Administração Pública construir sua noção de modernização e articular suas próprias ferramentas de administração para viabilizar sua modernização (Lopes, 2019). Todavia, para que esse desenvolvimento seja alcançado, é necessário a utilização de práticas gerencias com ênfase no uso de ferramentas de controle e de gestão que melhorem os resultados almejados pela sociedade (Diniz \& Santos, 2019).

\subsubsection{Eficiência e Eficácia na Administração Pública}

O atual cenário faz com que as organizações busquem mais agilidade, eficiência e também uma postura mais responsiva, mais complexa, mais diversificada e mais dinâmica frente à sociedade contemporânea (Pradella, 2013).

Na Administração Pública, o conceito de eficiência teve um marco legal, tornando-se um princípio jurídico acrescido ao artigo 37, caput, da Carta Magna a partir da emenda 19/1998. Essa emenda constitucional foi realizada na reforma gerencial, incluindo o princípio de eficiência aos demais princípios que regem a atividade administrativa e regulam as ações das organizações públicas e de seus respectivos agentes (Oliveira, 2015).

Para Guimarães e Carvalho (2020, p. 53) "a atuação da Administração Pública deve ser pautada em princípios, cabendo ao administrador acompanhar a prestação dos serviços pelos municípios".

A eficiência, na concepção clássica da Administração, era a palavra-chave explícita nas teorias. Mas o que estava implícito era a noção de equilíbrio do ambiente fora e dentro das organizações, por isso o foco era nos meios, pois se acreditava que todas as atividades e processos estavam em um contexto de estabilidade, de regularidade, de confiabilidade e de precisão (Naveira, 1998; Pinto \& Coronel, 2017).

A eficácia organizacional é um fenômeno que apresenta elevado grau de complexidade além de possuir um aspecto multidimensional, isto é, para acontecer, ela depende de vários aspectos distintos. Ademais, a eficácia está no centro das discussões teóricas e práticas de qualquer processo de gestão (Fernandes, 2008; Pinto \& Coronel, 2017).

\subsection{Orçamento público}

Para Bastos (1992) o objetivo do orçamento público é o de tornar-se um instrumento de exercício da democracia pelo qual os participantes exercem o direito, por intermédio de seus mandatários, de só verem efetivadas as despesas e permitidas as arrecadações tributárias que estiverem autorizadas pela lei orçamentária.

Segundo Pires e Mota (2006), foi com a vinda do rei D. João VI ao Brasil e a abertura dos portos, com consequente aumento nos impostos aduaneiros, que iniciou o "processo de organização das finanças públicas, culminando com a criação, em 1808, do Erário Público e do Regime de Contabilidade". 
Pires e Motta (2006, p. 41) ainda explicam que, foi a Constituição de 1988 que "atribuiu ao processo orçamentário uma seção especial e à parte: Titulo VI Da Tributação e do Orçamento, Capítulo II das Finanças Públicas, Seção II dos Orçamentos", trazendo grandes mudanças e uma nova visão quanto às práticas orçamentárias, inclusive para os Estados e para os Municípios.

Uma conceituação, de forma simplista, feita pela maioria dos autores consultados, define o orçamento público como sendo um instrumento de planejamento legal, que contém a previsão de receitas e de despesas que serão realizadas por um governo em um prazo determinado.

Orçamento público é o planejamento feito pela Administração Pública para atender, durante determinado período, aos planos e programas de trabalho por ela desenvolvidos, por meio da planificação das receitas a serem obtidas e pelos dispêndios a serem efetuados, objetivando a continuidade e a melhoria quantitativa e qualitativa dos serviços prestados à sociedade (Lima \& Castro, 2000, p.19).

O orçamento público deve ser elaborado anualmente pelo Poder Executivo constituído em cada uma das esferas de gestão (Federal, Estadual e Municipal), sendo encaminhado ao Poder Legislativo para aprovação, conforme expresso na Constituição Federal de 1988 e na Lei n 4.320/64.

\subsubsection{Leis Orçamentárias (LO)}

Nascimento (2006) afirma que a Constituição de 1988 teve a preocupação de institucionalizar a integração entre os processos de planejamento e de orçamento e de torna compulsória a elaboração de três instrumentos básicos para esse fim: o Plano Plurianual, o Orçamento Anual e a Lei de Diretrizes Orçamentárias.

Segundo Silva, Amorim e Silva (2004, p.39), o fortalecimento do processo orçamentário como uma peça para planejar e prevenir desequilíbrios indesejáveis veio após a publicação da LRF. E de acordo com Pereira (1999), desde a Constituição Federal de 1988, a elaboração do orçamento interage com o Plano Plurianual, a Lei de Diretrizes Orçamentárias e a Lei Orçamentária Anual de forma que metas e orçamentos estejam em consonância.

\subsubsection{Plano Plurianual (PPA)}

Conforme o Artigo 165, inciso I, da Constituição Federal (CF), o PPA é uma lei que estabelece as diretrizes, os objetivos e as metas governamentais a serem concretizadas no médio prazo, ou seja, abrangendo um período de quatro anos, editado no primeiro ano da gestão e alcança um ano da gestão subsequente, de sorte a atender ao princípio da continuidade de programas.

As inovações da Lei de Responsabilidade Fiscal (LRF) em relação ao dispositivo Art. $35, \S 2^{\circ}, A D C T$, é o prazo para o encaminhamento do projeto do Plano Plu- 
rianual. Sendo ele previsto até o dia $30 / 4$ do primeiro ano do mandato (Art. $3^{\circ}, \S 2^{\circ}$, $\mathrm{LRF}$ ), enquanto no Art. $35, \S 2^{\circ}, \mathrm{ADCT}, \mathrm{CF}$, o prazo é mais longo, até quatro meses antes do encerramento do primeiro exercício financeiro. Ou seja, 31/8 (Brasil, 2011).

O prazo para a devolução do projeto do Plano Plurianual para sanção é até o encerramento do primeiro período da sessão legislativa, ou seja, 30/6 (Art. $3^{\circ}$, caput, LRF), enquanto no Art. $35, \S 2^{\circ}, A D C T, C F$, o prazo é mais longo, até o encerramento da sessão legislativa. Isto é, 15/12 (Brasil, 2011, p.1675).

Pode-se citar entre os objetivos do PPA: esclarecer e determinar claramente as metas, as prioridades da administração e os resultados almejados; e elaborar e incrementar o planejamento, o orçamento e a gestão por programas em todos os órgãos da administração. Conclui-se, então, que a PPA é a expressão do que se pretende para o período de governo.

\subsubsection{Lei de Diretrizes Orçamentárias (LDO)}

O conteúdo da LDO está previsto no Art. 165, § $2^{\circ}$, da Constituição Federal, que estabelece:

$\S 2^{\circ}$ - A Lei de Diretrizes Orçamentárias compreenderá as metas e prioridades da administração pública federal, incluindo as despesas de capital para o exercício financeiro subsequente, orientará a elaboração da Lei Orçamentária Anual, disporá sobre as alterações na legislação tributária e estabelecerá a política de aplicação das agências financeiras oficiais de fomento (Brasil, 2011).

A LDO determina preceitos gerais, traça metas anuais e dirige quais os rumos devem ser colocados em prática e quais devem ser priorizados no decorrer do exercício financeiro. Seu intuito é de regular as ações de Governo, previstas no PPA, às reais possibilidades de caixa.

\subsubsection{Lei Orçamentária Anual (LOA)}

Segundo Albanez (2011), a Lei Orçamentária Anual (LOA) está prevista nos artigos 165, III, $\S 5^{\circ}$ a $8^{\circ}$, e 167, I, VIII e $\S 1^{\circ}$, da Constituição Federal (Brasil, 2011). É conhecida como Planejamento Operacional de curto prazo. Lei periódica só produz efeitos dentro do exercício financeiro, ou seja, dentro de 1 ano, conforme o Art. 35, da Lei 4.320/64. Lima (2016, apud Campos, 2005), enfatiza que estes embasamentos foram utilizados pelos gestores públicos para o cumprimento e para a busca dos controles, da eficiência e da transparência das ações planejadas, consolidando vários elementos fundamentais em matéria de gestão responsável das finanças públicas.

Dando continuidade ao referido Artigo da CF, a LOA é de competência privativa do Poder Executivo, deve ser formalizada conforme as orientações dadas na LDO e destacar os recursos do orçamento fiscal, da seguridade social e de 
investimentos de todas as unidades gestoras e das empresas que detenham a maioria do capital com direito a voto, não podendo constar dispositivos estranhos à previsão da receita ou fixação da despesa, salvo a autorização para a abertura de créditos suplementares e para a contratação de operações de crédito.

A LOA é encaminhada à Câmara até 30 de agosto, ou de acordo com o prazo estabelecido na Lei Orgânica do Município, o Poder Legislativo só poderá aprovar emendas ou modificações na LOA se estas forem compatíveis com o PPA e o LDO e indique a fonte de financiamento, desde que esta não seja relacionada a despesas programadas com pessoal e com serviço da dívida, de acordo com os artigos 165, § $8^{\circ}$ e 166, § $3^{\circ}$ da CF (Brasil, 2011).

O mecanismo mais importante de administrar o orçamento e o financeiro da Administração Pública é a LOA, em que seu principal intuito é coordenar o equilíbrio entre as receitas e as despesas públicas.

\subsection{Responsabilidade Fiscal (RF)}

A LRF, como ficou conhecida a Lei Complementar $n^{\circ} 101$, publicada no ano 2000 e vigente a partir de sua publicação, é conhecida popularmente como Lei de Responsabilidade Fiscal, ou simplesmente LRF, e pode ser considerada um marco na gestão pública no Brasil.

No que diz respeito ao modo de gerir a máquina administrativa, a LRF pode ser considerada como uma norteadora de ações imposta aos gestores públicos, exigindo desses um maior planejamento a respeito das despesas públicas, das receitas públicas e de seus limites ao passo que Ihes impõe maior controle e maior fiscalização na forma de agir, impondo-Ihes sanções e vedações em matéria orçamentária e financeira.

Para Figueiredo e Nobrega (2005) a responsabilidade na gestão fiscal, recorrente conceito no texto da lei, pode ser traduzida como a atuação responsável na arrecadação das receitas e na realização das despesas.

Os referidos autores afirmam, ainda, perceber que é tentado impor um novo padrão de conduta fiscal aos gestores, tendo como pressupostos: ação planejada e transparente. A Lei de Responsabilidade Fiscal pode-se dizer que se apoia em quatro pilares principais: o planejamento, o controle, a transparência e a responsabilização, que serão abordados adiante.

Na Administração Pública, o planejamento é um mecanismo essencial. Tanto que a Constituição Federal, em seu Artigo 174, já prevê a obrigatoriedade de sua elaboração "como regulador da atividade econômica, o Estado exercerá, na forma da lei, as funções de fiscalização, incentivo e planejamento, sendo este determinante para o setor público".

No planejamento, o Governo (Federal, Estadual ou Municipal) se compromete, num período de 04 anos, a programar, de forma regionalizada, um plano de investimentos prioritários voltados ao crescimento de uma Nação/Estado/Município. 
A LRF prevê um mecanismo de maior controle nas contas públicas, em que passa a haver maior rigor para que o governo não contraia empréstimos ou dívidas. É um mecanismo de fiscalização e de transparência. Em seu Art. 59, a LRF determina que "o Poder Legislativo, diretamente ou com o auxílio dos Tribunais de Contas, e o sistema de controle interno de cada Poder e do Ministério Público" são os responsáveis pela fiscalização e pelo cumprimento das suas normas (Brasil, 2011).

Neste sentido, o controle é entendido como forma de "[...] vigilância, orientação e correção que um Poder, órgão ou autoridade exerce sobre a conduta funcional do outro". Serve como uma defesa da própria administração e dos direitos do povo que por ela é representado (Meirelles, 2003, p.641).

A LRF trouxe uma colaboração muito importante para a transparência da gestão fiscal ao definir que os relatórios fiscais devam ter ampla divulgação, assegurando inclusive a participação da sociedade na discussão dos PPA, LDO e LOA.

Um dos instrumentos para que a transparência se efetive é a audiência pública, definida pela LRF com a finalidade de oferecer à sociedade oportunidade de participar nas decisões políticas de alocação dos recursos públicos, exercitar o princípio da transparência e motivar o controle social dos atos da administração.

O administrador que deixar de cumprir com as imposições da LRF, estará sujeito às penalidades que também podem ser chamadas de sanções. Existem dois tipos de sanções: as dispostas na própria LRF e as pessoais previstas na Lei Ordinária que trata de Crimes de Responsabilidade Fiscal (Lei $\left.n^{\circ} 10.028 / 2000\right)$. E, ainda, segundo a LRF, os Tribunais de Contas ficam encarregados de fiscalizar o cumprimento das normas (Brasil, 2000).

\section{PROCEDIMENTOS METODOLÓGICOS}

Para que uma pesquisa seja bem definida, faz-se necessário seguir critérios preestabelecidos, uma vez que dentro dela, almeja-se a obtenção de respostas ao problema proposto, com base nos procedimentos adequados de coleta de dados.

Para tanto, a metodologia adotada, quanto aos objetivos, tem caráter exploratório e a pesquisa bibliográfica em livros, em legislações específicas e em artigos extraídos da internet. De acordo com Fonteles et.al. (2009), este tipo de pesquisa visa a uma primeira aproximação do pesquisador com o tema, para torná-lo mais familiarizado com os fatos e os fenômenos relacionados ao problema a ser estudado. No estudo, o investigador irá buscar subsídios não apenas para determinar a relação existente, mas, sobretudo, para conhecer o tipo de relação.

Quanto à abordagem, a pesquisa é qualitativa, com os dados obtidos através de uma pesquisa de campo mediante a aplicação de um questionário direcionado diretamente aos vereadores, tendo como tema tanto à compreensão deles perante a RIDE polo Petrolina-Juazeiro quanto sua compreensão acerca da LRF, assim como seu conhecimento sobre o cumprimento da eficiência e da eficácia dessa lei. O universo da pesquisa foi composto pelas cidades de Petrolina, Lagoa 
Grande, Santa Maria e Orocó, pertencentes ao Estado de Pernambuco, e Casa Nova, Curaçá, Sobradinho e Juazeiro, pertencentes ao Estado da Bahia.

Matias e Pereira (2007), ao falar dos questionários como fonte de coleta de dados, explanam que esses correspondem a um conjunto de perguntas que devem ser respondidas pelo informante.

Quanto a elaboração dos questionários, o instrumento utilizado nas entrevistas, durante o estudo realizado no ano de 2018, foi o formulário semiestruturado composto por 21 questões fechadas, para julgar certo ou errado.

Com relação ao universo de pesquisa no RIDE polo Petrolina-Juazeiro, as câmaras são compostas por 116 vereadores, porém a amostra utilizada para realização da pesquisa foi a amostragem desproporcional, não probabilística, que é utilizada quando há grupos e subgrupos que geram resultados com pesos dessemelhantes em uma pesquisa. Com isso, levou-se em consideração as respostas de apenas 47 vereadores. Como dito anteriormente, o instrumento de coleta de dados foi a aplicação de questionário referente ao perfil do entrevistado, em que foram elaboradas 5 perguntas, que seriam sobre: a idade dos vereadores; o seu grau de instrução; o seu tempo de atuação como vereador; a frequência que realiza cursos sobre a LRF e o total de cursos que já realizou. No tocante aos itens da LRF, os dados constam no Quadro 1:

Quadro 1 - Questões apresentadas aos vereadores.

\begin{tabular}{|c|l|}
\hline $\mathbf{1}^{\circ}$ & $\begin{array}{l}\text { A Lei Complementar n. }{ }^{\circ} \text { 101/2000. A LRF aplica-se a todos os entes da } \\
\text { Federação. }\end{array}$ \\
\hline $\mathbf{2}^{\circ}$ & São entes da Federação: Apenas a União e os Municípios \\
\hline $\mathbf{3}^{\circ}$ & $\begin{array}{l}\text { A Lei de Responsabilidade Fiscal, por ser uma lei complementar, não pode } \\
\text { estabelecer normas que orientam as finanças públicas no país. }\end{array}$ \\
\hline $\mathbf{4}^{\circ}$ & $\begin{array}{l}\text { A Lei de Responsabilidade Fiscal se apoia em quatro eixos: o planejamento, a } \\
\text { transparência, o controle e a responsabilização. }\end{array}$ \\
\hline $\mathbf{5}^{\circ}$ & $\begin{array}{l}\text { A LRF prevê que a Lei de Diretrizes Orçamentárias disponha sobre alterações na } \\
\text { legislação tributária. }\end{array}$ \\
\hline $\mathbf{6}^{\circ}$ & $\begin{array}{l}\text { Proibições do Presidente, Governador ou Prefeito Municipais, no tocante as } \\
\text { Operações de Crédito por Antecipação de Receita Orçamentária proíbem que no } \\
\text { último ano de mandato. }\end{array}$ \\
\hline $\mathbf{7}^{\circ}$ & $\begin{array}{l}\text { O projeto da Lei de Diretrizes Orçamentárias (LDO) deverá conter o Anexo de } \\
\text { Metas Fiscais anuais com o montante da dívida pública para o exercício a que se } \\
\text { refere e para os três seguintes. }\end{array}$ \\
\hline $\mathbf{8}^{\circ}$ & $\begin{array}{l}\text { Receita corrente líquida, sociedade cuja maioria do capital social com direito a voto } \\
\text { pertença, direta ou indiretamente, a ente da Federação. }\end{array}$ \\
\hline $\mathbf{9}^{\circ}$ & $\begin{array}{l}\text { Não está incluso nos objetivos da LRF o estabelecimento de normas para a } \\
\text { elaboração e para o controle dos orçamentos públicos. }\end{array}$ \\
\hline $\mathbf{1 0}^{\circ}$ & $\begin{array}{l}\text { O estabelecimento de normas de finanças públicas voltadas para a gestão fiscal é } \\
\text { um dos objetivos da LRF. }\end{array}$ \\
\hline $\mathbf{1 1}^{\circ}$ & $\begin{array}{l}\text { A garantia do equilíbrio das contas públicas, por meio de metas de resultados entre } \\
\text { receitas e despesas é um dos objetivos da LRF. }\end{array}$ \\
\hline
\end{tabular}




\begin{tabular}{|c|l|}
\hline $12^{\circ}$ & $\begin{array}{l}\text { A LRF prevê como medida obrigatória realizar limitação de empenho e de } \\
\text { movimentação financeira. }\end{array}$ \\
\hline $\mathbf{1 3}^{\circ}$ & $\begin{array}{l}\text { A LRF estabeleceu tetos diferentes para o gasto com pessoal no interior de cada } \\
\text { uma das esferas do governo, definidos como percentual da receita corrente líquida. }\end{array}$ \\
\hline $\mathbf{1 4}^{\circ}$ & $\begin{array}{l}\text { Os governos, estadual e municipal, não podem gastar com funcionalismo público } \\
\text { até } 60 \% \text { da receita corrente líquida. }\end{array}$ \\
\hline $\mathbf{1 5}^{\circ}$ & $\begin{array}{l}\text { A lei permite que os governos ultrapassem, por um breve período, o limite de } \\
\text { endividamento. }\end{array}$ \\
\hline $16^{\circ}$ & $\begin{array}{l}\text { No que se refere à elaboração do PPA, o planejamento governamental não foi } \\
\text { afetado pela aprovação da LRF. }\end{array}$ \\
\hline $17^{\circ}$ & $\begin{array}{l}\text { A LRF exercita o princípio da transparência e motiva o controle social dos atos da } \\
\text { administração. }\end{array}$ \\
\hline $18^{\circ}$ & O não cumprimento com as imposições da LRF não estará sujeito a penalidades. \\
\hline $19^{\circ}$ & $\begin{array}{l}\text { Os Tribunais de Contas ficam encarregados de fiscalizar o cumprimento das } \\
\text { normas da LRF. }\end{array}$ \\
\hline $\mathbf{2 0}^{\circ}$ & $\begin{array}{l}\text { A LRF prevê um mecanismo de maior controle nas contas públicas, passando a } \\
\text { haver maior rigor para que o governo não contraia empréstimos ou dívidas. }\end{array}$ \\
\hline $\mathbf{2 1 ^ { \circ }}$ & $\begin{array}{l}\text { Lei estadual ou municipal poderá fixar limites superiores àqueles previstos na LRF } \\
\text { para as dívidas consolidada e mobiliária, operações de crédito e concessão de } \\
\text { garantias. }\end{array}$ \\
\hline
\end{tabular}

Fonte: Elaborado pelo autor, com dados da LRF (2000).

No Quadro 1, foram dispostos itens que são apresentados na LRF e que são considerados essenciais para o seu entendimento. Sabe-se que para os servidores públicos e para os gestores públicos, é fundamental o entendimento da LRF, já que ela aborda acerca das responsabilizações das ações e dos procedimentos que são realizados dentro dos órgãos públicos.

A LRF aborda tanto sobre as responsabilidades dos gestores públicos quanto sobre as contas públicas, como também estabelece limites que não podem ser excedidos por parte dos órgãos, evitando, assim, sanções legais, como por exemplo a não transferências de recursos por parte do Governo Federal.

E é através da exposição desses itens que se apurou os acertos e os erros por parte dos respondentes, em que para cada item do questionário específico, há apenas uma resposta, e pediu-se para marcar se aquele item está correto ou incorreto ou para não opinar.

\section{ANÁLISE DOS RESULTADOS E DISCUSSÃO}

Coletou-se os dados, através da aplicação de questionários contendo 21 perguntas acerca da Lei de Responsabilidade Fiscal (LRF), Lei $n^{\circ} 101$ de 04 de maio de 2000, a 47 vereadores da RIDE polo Petrolina-Juazeiro com o objetivo de identificar o nível de compressão desses a respeito da LRF. Além de identificar as principais falhas que ocorrem nas câmaras municipais com relação à reciclagem dos parlamentares sobre a LRF. 
Através dos questionários, buscou-se, nas questões iniciais, identificar algumas características dos respondentes, ou seja, o perfil dos entrevistados, tais como idade, grau de instrução, tempo de atuação como vereador, frequência em que são feitos cursos de atualização sobre a LRF e número de participação nesses cursos.

A segunda parte do questionário aborda os aspectos específicos, através de questionamentos acerca da LRF, identificando assim os erros e acertos acerca de itens que compõem essa lei. O Gráfico 1 apresenta a faixa etária dos vereadores que responderam os questionários e que fazem parte do governo das cidades pesquisadas:

Gráfico 1 - Faixa Etária

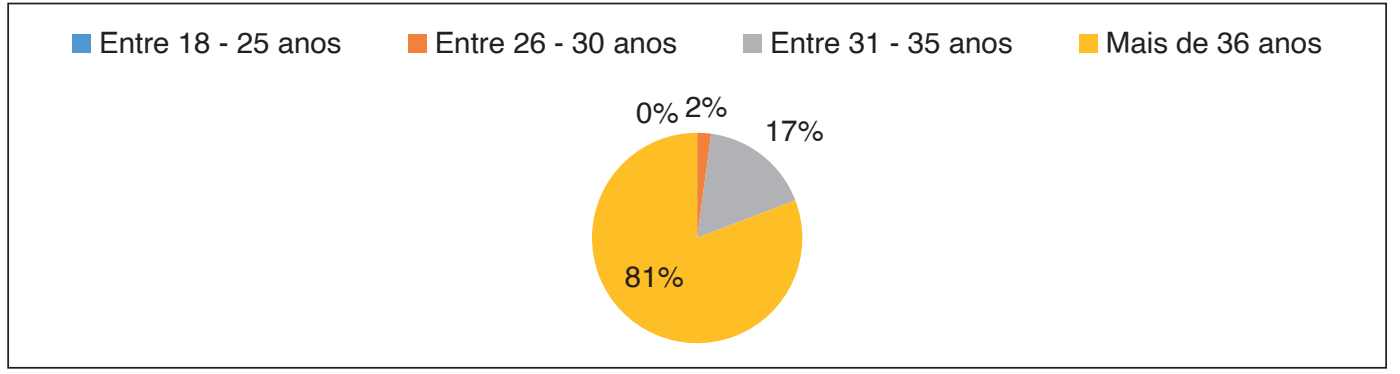

Fonte: Dados da Pesquisa.

A maior parcela dos vereadores entrevistados possui mais de 36 anos (81\%), enquanto aqueles que possuem idade entre 31 a 35 anos representaram 17\% e aqueles que possuíam idade entre 26 e 30 anos representaram $2 \%$ da amostra. $\mathrm{O}$ Gráfico 2 apresenta o grau de instrução dos vereadores, se eles se enquadram no nível fundamental, no médio, no superior ou no nível de pós-graduação:

Gráfico 2- Grau de Instrução

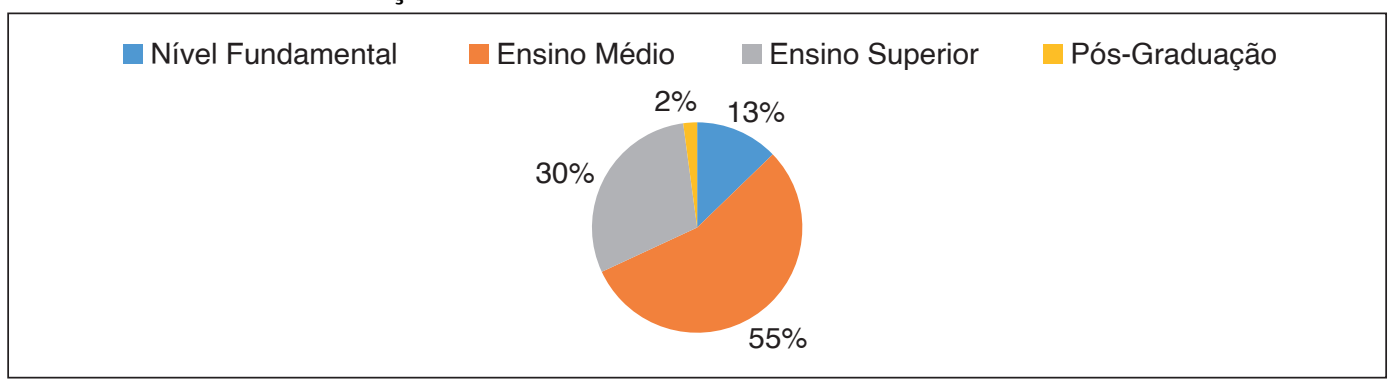

Fonte: Dados da Pesquisa.

Com base na pesquisa, mais da metade dos vereadores possui ensino médio (55\%), enquanto $30 \%$ possuem ensino superior e apenas $2 \%$ possui pós-graduação. Em outras pesquisas, seria pertinente analisar em que área esses vereadores possuem formação, como por exemplo na área de direito e na área 
de contabilidade, que envolve a Lei de Responsabilidade Fiscal (LRF). Questionou-se, ainda, quanto tempo os entrevistados atuam como vereador e o Gráfico 3 sintetiza esses dados:

Gráfico 3- Atuação como Vereador

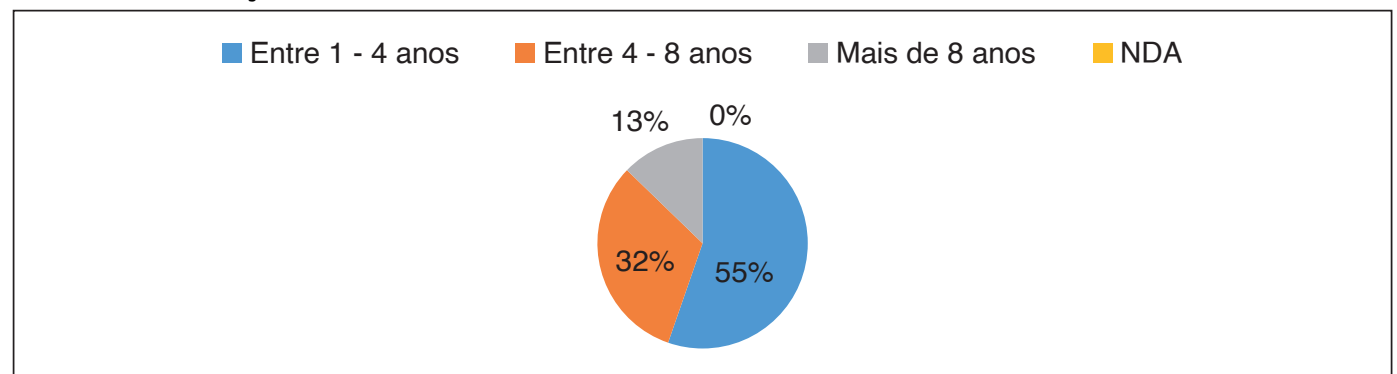

Fonte: Dados da Pesquisa.

Percebe-se através da pesquisa que mais da metade dos vereadores pesquisados (55\%) possui entre 1 a 4 anos de atuação como vereador, ou seja, um mandato, enquanto $32 \%$ possui entre 4 a 8 anos (32\%) e 13\% possui mais de 8 anos de atuação.

Perguntou-se ainda com que frequência são realizados cursos a respeito da Lei de Responsabilidade Fiscal e, através do Gráfico 4, podemos observar os seguintes achados:

Gráfico 4- Frequência de Realização de Cursos

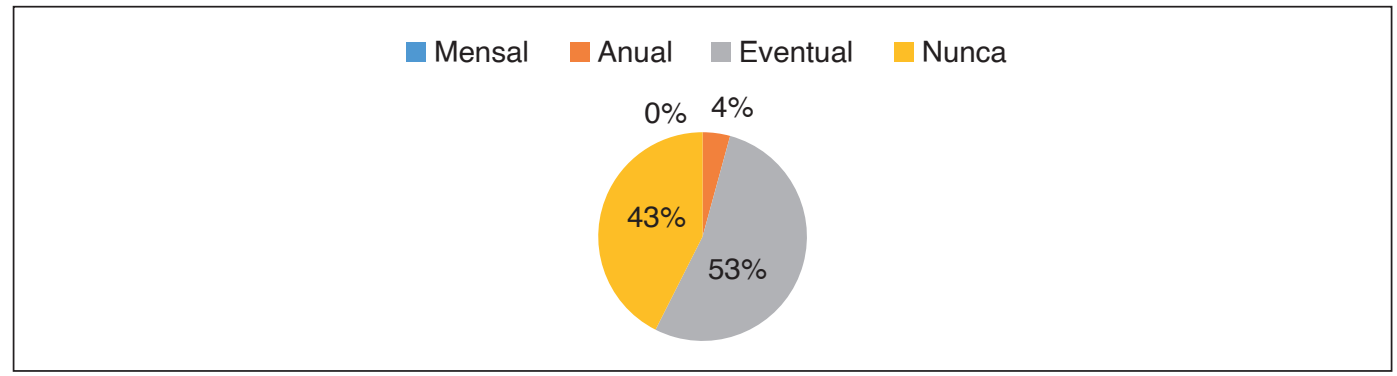

Fonte: Dados da Pesquisa.

Notou-se através do Gráfico 4 que 53\% dos vereadores afirmaram que realizam cursos eventualmente, enquanto $43 \%$ afirmaram que nunca realizam cursos a respeito da LRF e 4\% afirmaram que realizam cursos nessa área anualmente. Isso demonstra que ainda falta uma maior qualificação dos vereadores quanto aspectos importantes da gestão pública, haja vista que a LRF é uma lei essencial nas práticas governamentais.

Além de questionar sobre a realização de cursos por parte dos vereadores, pesquisou-se também quantos cursos a respeito da LRF foram realizados pelos vereadores, conforme Gráfico 5: 
Gráfico 5- Cursos Realizados sobre LRF

\begin{tabular}{|c|c|}
\hline Entre 1 - 4 cursos $\quad$ Entre 4 - 8 cursos Nenhum de 8 cursos \\
$0 \% 2 \%$
\end{tabular}

Fonte: Dados da Pesquisa.

Ao questionar sobre a realização de cursos pertinentes a LRF, percebeu que $51 \%$ dos vereadores realizaram entre 1 e 4 cursos, enquanto $47 \%$ afirmaram não terem realizado nenhum curso e $2 \%$ disseram que realizaram entre 4 e 8 cursos. Através desses dados, é notório que ainda falta qualificação por parte dos vereadores acerca da LRF. O Quadro 2 apresenta os acertos que foram apresentados pelos vereadores dos municípios da RIDE que fazem parte do Estado de Pernambuco:

Quadro 2 - Acertos do Questionário (Municípios de Pernambuco)

\begin{tabular}{|c|c|c|c|c|c|c|c|c|}
\hline \multirow{3}{*}{ QUESTÃO } & \multicolumn{4}{|c|}{ Pernambuco } & \multirow{2}{*}{\multicolumn{4}{|c|}{ ACERTOS PE }} \\
\hline & \multirow{2}{*}{\begin{tabular}{|c|} 
Orocó - \\
PE
\end{tabular}} & \multirow{2}{*}{\begin{tabular}{|c|} 
Santa Maria - \\
PE
\end{tabular}} & \multirow{2}{*}{$\begin{array}{c}\text { Lagoa Grande - } \\
\text { PE }\end{array}$} & \multirow{2}{*}{$\begin{array}{l}\text { Petrolina - } \\
\text { PE }\end{array}$} & & & & \\
\hline & & & & & F.A. & F.R. (\%) & F.A. & F.R. (\%) \\
\hline Questão 1 & 4 & 3 & 3 & 6 & 16 & $94 \%$ & 1 & $6 \%$ \\
\hline Questão 2 & 3 & 3 & 2 & 5 & 13 & $76 \%$ & 4 & $24 \%$ \\
\hline Questão 3 & 2 & 2 & 2 & 3 & 9 & $53 \%$ & 8 & $47 \%$ \\
\hline Questão 4 & 3 & 3 & 3 & 4 & 13 & $76 \%$ & 4 & $24 \%$ \\
\hline Questão 5 & 3 & 0 & 4 & 5 & 12 & $71 \%$ & 5 & $29 \%$ \\
\hline Questão 6 & 4 & 2 & 2 & 1 & 9 & $53 \%$ & 8 & $47 \%$ \\
\hline Questão 7 & 1 & 3 & 1 & 3 & 8 & $47 \%$ & 9 & $53 \%$ \\
\hline Questão 8 & 2 & 2 & 3 & 4 & 11 & $65 \%$ & 6 & $35 \%$ \\
\hline Questão 9 & 3 & 3 & 4 & 3 & 13 & $76 \%$ & 4 & $24 \%$ \\
\hline Questão 10 & 2 & 3 & 4 & 2 & 11 & $65 \%$ & 6 & $35 \%$ \\
\hline Questão 11 & 1 & 1 & 3 & 5 & 10 & $59 \%$ & 7 & $41 \%$ \\
\hline Questão 12 & 2 & 3 & 2 & 3 & 10 & $59 \%$ & 7 & $41 \%$ \\
\hline Questão 13 & 1 & 1 & 3 & 2 & 7 & $41 \%$ & 10 & $59 \%$ \\
\hline Questão 14 & 2 & 2 & 3 & 4 & 11 & $65 \%$ & 6 & $35 \%$ \\
\hline Questão 15 & 3 & 3 & 4 & 3 & 13 & $76 \%$ & 4 & $24 \%$ \\
\hline Questão 16 & 3 & 2 & 1 & 2 & 8 & $47 \%$ & 9 & $53 \%$ \\
\hline Questão 17 & 2 & 2 & 1 & 3 & 8 & $47 \%$ & 9 & $53 \%$ \\
\hline Questão 18 & 4 & 1 & 2 & 1 & 8 & $47 \%$ & 9 & $53 \%$ \\
\hline Questão 19 & 4 & 3 & 4 & 5 & 16 & $94 \%$ & 1 & $6 \%$ \\
\hline Questão 20 & 3 & 2 & 3 & 4 & 12 & $71 \%$ & 5 & $29 \%$ \\
\hline Questão 21 & 2 & 2 & 2 & 1 & 7 & $41 \%$ & 10 & $59 \%$ \\
\hline TOTAL & 54 & 46 & 56 & 69 & 225 & & & \\
\hline
\end{tabular}

Fonte: Dados da Pesquisa.

Notas: F.A = Frequência Absoluta/ F.R = Frequência Relativa em \%. 
O Quadro 2 apresenta a quantidade de acertos por parte dos municípios, por questões, conforme os itens que foram apresentados no Quadro 1. Percebeu-se que há uma oscilação com relação aos acertos por parte dos municípios pernambucanos. As questões que menos apresentaram acertos foram as questões 13 e 21.

As questões 13 e 21 abordam sobre o limite e os tetos para os gastos com pessoal e dívidas consolidadas e mobiliárias, como também as operações de crédito e de concessões de garantias. Isso indica que os vereadores do Estado de Pernambuco ainda precisam de uma qualificação nesse sentido.

Já as questões que apresentaram maiores acertos foram as 1 e 19, que abordam sobre a aplicabilidade da LRF pelos entes da Federação e sobre a responsabilidade dos Tribunais de Contas no cumprimento das normas da LRF. Buscou-se sintetizar, no Gráfico 6, o percentual dos acertos e dos erros por parte dos municípios pernambucanos:

Gráfico 6 - Média de Acertos e Erros em Percentual (Municípios de Pernambuco)

\begin{tabular}{|c|c|c|c|c|c|c|}
\hline $64 \%$ & $73 \%$ & $27 \%$ & $67 \%$ & $33 \%$ & $55 \%$ & $45 \%$ \\
\hline \multirow[t]{2}{*}{ Orocó - PE } & \multicolumn{2}{|c|}{ Santa Maria - PE } & \multicolumn{2}{|c|}{ Lagoa Grande - PE } & \multicolumn{2}{|c|}{ Petrolina- PE } \\
\hline & & Acertos & Erros & & & \\
\hline
\end{tabular}

Fonte: Dados da Pesquisa.

Com base no Gráfico 6, percebeu-se que Santa Maria foi o município que apresentou um maior percentual de acertos, chegando a $73 \%$, enquanto que os municípios de Orocó e de Lagoa Grande foram os que apresentaram percentuais semelhantes, $64 \%$ e $67 \%$, respectivamente. Petrolina foi o município que apresentou o menor percentual de acertos, chegando a $55 \%$.

Realizando a mesma análise com os municípios que compõe a RIDE, mas que são do Estado da Bahia, percebeu-se através do Quadro 3, que as cidades apresentaram as seguintes quantidades de acertos:

Quadro 3 - Acertos do Questionário (Municípios da Bahia)

\begin{tabular}{|c|c|c|c|c|c|c|c|c|}
\hline \multirow{3}{*}{ QUESTÃO } & \multicolumn{4}{|c|}{ Bahia } & \multirow{2}{*}{\multicolumn{4}{|c|}{ ACERTOS BA }} \\
\hline & \multirow{2}{*}{$\begin{array}{c}\text { Juazeiro - } \\
\text { BA }\end{array}$} & \multirow{2}{*}{$\begin{array}{c}\text { Sobradinho - } \\
\text { BA }\end{array}$} & \multirow{2}{*}{$\begin{array}{c}\text { Casa Nova - } \\
\text { BA }\end{array}$} & \multirow{2}{*}{$\begin{array}{c}\text { Curaçá - } \\
\text { BA }\end{array}$} & & & & \\
\hline & & & & & F.A. & F.R. (\%) & F.A. & F.R. (\%) \\
\hline Questão 1 & 11 & 9 & 4 & 4 & 28 & $93 \%$ & 2 & $7 \%$ \\
\hline Questão 2 & 11 & 9 & 5 & 3 & 28 & $93 \%$ & 2 & $7 \%$ \\
\hline Questão 3 & 6 & 1 & 3 & 2 & 12 & $40 \%$ & 18 & $60 \%$ \\
\hline Questão 4 & 11 & 9 & 4 & 3 & 27 & $90 \%$ & 3 & $10 \%$ \\
\hline Questão 5 & 9 & 8 & 2 & 2 & 21 & $70 \%$ & 9 & $30 \%$ \\
\hline
\end{tabular}




\begin{tabular}{|c|c|c|c|c|c|c|c|c|}
\hline Questão 6 & 7 & 5 & 5 & 4 & $\mathbf{2 1}$ & $\mathbf{7 0 \%}$ & $\mathbf{9}$ & $\mathbf{3 0 \%}$ \\
\hline Questão 7 & 9 & 6 & 3 & 3 & $\mathbf{2 1}$ & $\mathbf{7 0 \%}$ & $\mathbf{9}$ & $\mathbf{3 0 \%}$ \\
\hline Questão 8 & 9 & 5 & 1 & 1 & $\mathbf{1 6}$ & $\mathbf{5 3 \%}$ & $\mathbf{1 4}$ & $\mathbf{4 7 \%}$ \\
\hline Questão 9 & 6 & 4 & 1 & 2 & $\mathbf{1 3}$ & $\mathbf{4 3 \%}$ & $\mathbf{1 7}$ & $\mathbf{5 7 \%}$ \\
\hline Questão 10 & 9 & 6 & 4 & 4 & $\mathbf{2 3}$ & $\mathbf{7 7 \%}$ & $\mathbf{7}$ & $\mathbf{2 3} \%$ \\
\hline Questão 11 & 9 & 6 & 5 & 3 & $\mathbf{2 3}$ & $\mathbf{7 7 \%}$ & $\mathbf{7}$ & $\mathbf{2 3} \%$ \\
\hline Questão 12 & 11 & 9 & 2 & 2 & $\mathbf{2 4}$ & $\mathbf{8 0 \%}$ & $\mathbf{6}$ & $\mathbf{2 0 \%}$ \\
\hline Questão 13 & 6 & 5 & 2 & 3 & $\mathbf{1 6}$ & $\mathbf{5 3 \%}$ & $\mathbf{1 4}$ & $\mathbf{4 7 \%}$ \\
\hline Questão 14 & 10 & 9 & 0 & 1 & $\mathbf{2 0}$ & $\mathbf{6 7 \%}$ & $\mathbf{1 0}$ & $\mathbf{3 3 \%}$ \\
\hline Questão 15 & 8 & 5 & 0 & 4 & $\mathbf{1 7}$ & $\mathbf{5 7 \%}$ & $\mathbf{1 3}$ & $\mathbf{4 3} \%$ \\
\hline Questão 16 & 3 & 3 & 3 & 2 & $\mathbf{1 1}$ & $\mathbf{3 7 \%}$ & $\mathbf{1 9}$ & $\mathbf{6 3 \%}$ \\
\hline Questão 17 & 8 & 9 & 5 & 3 & $\mathbf{2 5}$ & $\mathbf{8 3 \%}$ & $\mathbf{5}$ & $\mathbf{1 7 \%}$ \\
\hline Questão 18 & 10 & 9 & 5 & 2 & $\mathbf{2 6}$ & $\mathbf{8 7 \%}$ & $\mathbf{4}$ & $\mathbf{1 3 \%}$ \\
\hline Questão 19 & 9 & 9 & 5 & 4 & $\mathbf{2 7}$ & $\mathbf{9 0 \%}$ & $\mathbf{3}$ & $\mathbf{1 0 \%}$ \\
\hline Questão 20 & 7 & 8 & 5 & 3 & $\mathbf{2 3}$ & $\mathbf{7 7 \%}$ & $\mathbf{7}$ & $\mathbf{2 3 \%}$ \\
\hline Questão 21 & 4 & 6 & 3 & 2 & $\mathbf{1 5}$ & $\mathbf{5 0 \%}$ & $\mathbf{1 5}$ & $\mathbf{5 0 \%}$ \\
\hline TOTAL & $\mathbf{1 5 1}$ & $\mathbf{1 2 2}$ & $\mathbf{5 8}$ & $\mathbf{5 0}$ & $\mathbf{3 8 1}$ & & & \\
\hline
\end{tabular}

Fonte: Dados da Pesquisa.

Notas: F.A = Frequência Absoluta/ F.R = Frequência Relativa em \%.

De acordo com o Quadro 3, percebeu-se que, assim como ocorreu com os vereadores do Estado de Pernambuco, a questão 1 apresentou maiores quantidades de acertos por parte dos vereadores da Bahia, assim como a questão 2 que apresentaram 28 acertos. Enquanto que a questão 16 apresentou menores quantidades de acertos.

As questões 1 e 2 abordam sobre a aplicação da LRF e a classificação dos entes da Federação. Com isso, notou-se que, em relação a essas informações básicas, os vereadores marcaram corretamente. Já a questão 16, que apresentou maiores quantidades de erros, abordara sobre a afetação da LRF, no que tange a elaboração do Plano Plurianual, e a maior parte dos vereadores da Bahia marcaram essa questão de forma incorreta.

Assim como foi realizado na análise do Estado de Pernambuco, elaborou-se um gráfico com a quantidade total de vereadores dos municípios que compõe a RIDE, mas que fazem parte do Estado da Bahia, e a média de vereadores que acertaram as questões, conforme Gráfico 7:

Gráfico 7- Média de Acertos e Erros em Percentual (Municípios da Bahia)

\begin{tabular}{|c|cccccc|}
\hline $65 \%$ & $35 \%$ & $65 \%$ & $46 \%$ & $54 \%$ & $60 \%$ & $40 \%$ \\
\hline Juazeiro -BA & Sobradinho - BA & Casa Nova - BA & Curaçá - BA \\
Acertos & a Erros & \\
\hline
\end{tabular}

Fonte: Dados da Pesquisa. 
Dentre os municípios da Bahia, de Juazeiro e de Sobradinho, apresentaram, cada um, $65 \%$ de acertos, enquanto o que apresentou os menores percentuais de acertos foi o município de Casa Nova/BA, com 46\%. Após concluir toda análise, buscou-se através do Gráfico 8, apresentar qual dos Estados apresentou maior número de acertos:

Gráfico 8 - Erros e Acertos (Estados de Pernambuco e Bahia)

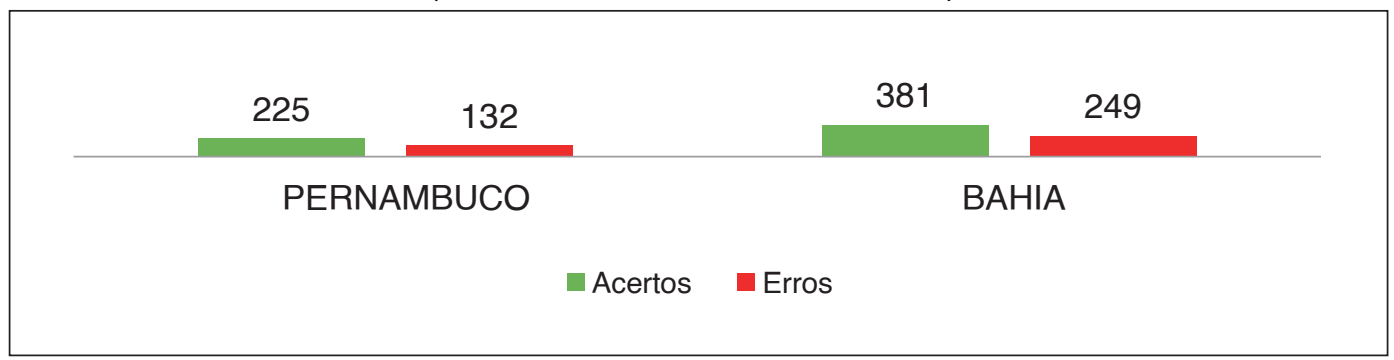

Fonte: Dados da Pesquisa.

A partir do Gráfico 8, percebeu-se que os vereadores que compõe a RIDE no Estado de Pernambuco tiveram acertos que chegaram a $63 \%$, enquanto que os vereadores do Estado da Bahia tiveram acertos que chegaram a $60 \%$, ou seja, a diferença de entendimento da LRF pelos vereadores do polo, tanto da Bahia como de Pernambuco, são mínimas, haja vista que o percentual de acertos se apresentou semelhante.

Isso corrobora com os dados apresentados anteriormente, no qual quase $50 \%$ dos respondentes afirmaram nunca realizarem cursos, como também quase metade dos respondentes enfatizaram que nunca realizaram cursos pertinentes a LRF. Por fim, o Gráfico 9 apresenta o ranking dos municípios com relação aos acertos apresentados referente aos itens da LRF:

Gráfico 9 - Ranking do Percentual de acertos por Municípios

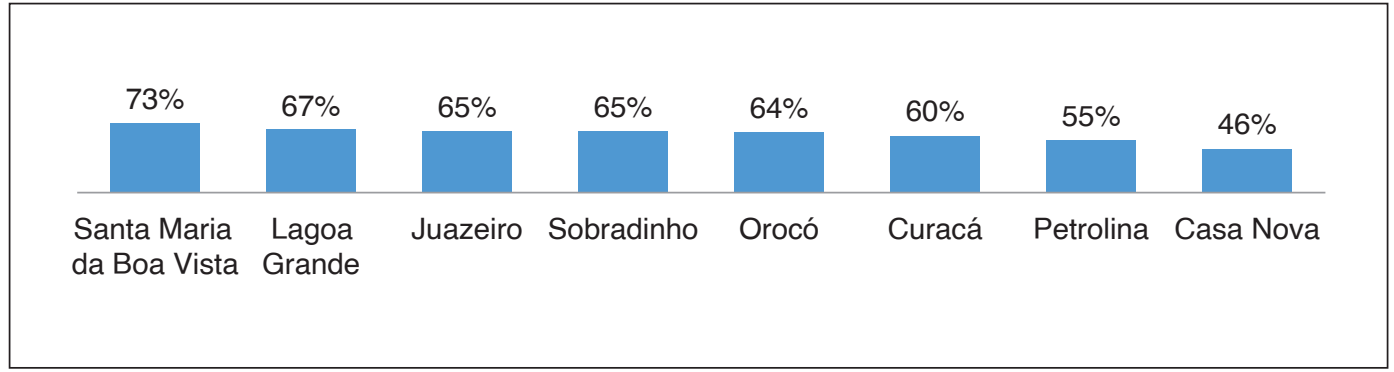

Fonte: Dados da Pesquisa.

O município que apresentou uma maior quantidade de acertos foi o de Santa Maria da Boa Vista/PE, já que de 21 questões, os vereadores acertaram em média $73 \%$ das questões, enquanto que o município que apresentou menor número médio de acertos foi o de Casa Nova, em que de 21 questões, eles acertaram 46\%. 


\section{CONSIDERAÇÕES FINAIS}

A pesquisa teve como objetivo verificar a compreensão dos vereadores integrantes da RIDE polo Petrolina-Juazeiro, acerca da Lei de Responsabilidade Fiscal, já que para o Legislativo Municipal essa lei é de grande importância (peso). Conforme constatado nos relatos dos respondentes, o Legislativo Municipal da RIDE precisa passar por aprimoramentos, pois ainda falta um maior investimento em qualificações no que tange a essa legislação.

Percebeu-se que a maior parte dos vereadores da RIDE que responderam o questionário, cerca de 55\%, atuam como vereador a pelo menos 4 anos. Além disso, enquanto que boa parte dos respondentes (cerca de 50\%) afirmaram nunca terem participado de cursos, a outra parte afirmou participarem somente eventualmente.

Sabe-se que é imprescindível a qualificação dos servidores públicos, já que só assim é possível ampliar os conhecimentos e sanar possíveis dúvidas que eles possuem quanto à aplicabilidade da lei. Quando questionados sobre a realização de cursos específicos que abordavam sobre a LRF, 51\% realizaram apenas de 1 a 4 cursos, um número considerado baixo para uma lei tão essencial no setor público.

Constatou-se ainda que, permanecia, até o período que essa pesquisa foi realizada, uma certa dificuldade por parte dos vereadores no entendimento da LRF, já que, em média, os acertos chegaram a um percentual de $60 \%$, ou seja, para uma lei que é tão usual, ainda é considerado um percentual baixo.

Ao realizar a análise de qual Estado apresentou um maior índice de acertos, notou-se que o Estado de Pernambuco apresentou um pouco mais de acertos, chegando a um percentual de $63 \%$, enquanto a Bahia apresentou $60 \%$.

Merecem destaque ainda os vereadores do município de Santa Maria da Boa Vista, que acertaram $73 \%$ das 21 questões apresentadas, e os vereadores do município de Casa Nova, que foram os que menos acertaram as questões que foram propostas, cerca de $46 \%$ acertos para um total de 21 questões.

Por fim, a pesquisa denota que os vereadores possuem conhecimento razoável da Lei Complementar $n^{\circ} 101 / 2000$, a LRF, mas reconhecem que existe a necessidade da administração das câmaras municipais incentivarem os vereadores, oferecendo-os cursos a respeito da referida lei, atuando assim de maneira correta na legislatura, já que a LRF é um pilar importante para o legislador.

Dentre as dificuldades da pesquisa, a maior foi a disponibilidade por parte dos vereadores em responder os questionários e a dificuldade de reuni-los, a fim de realizar a pesquisa, pois a maioria só aparece em dias de sessões e algumas vezes não apresentavam os questionários respondidos.

O estudo limitou-se a verificar o nível de compreensão dos vereadores da RIDE polo Petrolina-Juazeiro, já que a região analisada é considerada importante no desenvolvimento do país. E os mesmos têm como papel principal ser fiscalizador do executivo municipal. 
Pode-se considerar que o objetivo da pesquisa foi alcançado, já que se percebeu que o nível de conhecimento dos vereadores que se propuseram a responder o questionário é razoável e que o legislativo municipal ainda precisa atualizá-lo com mais frequência na busca de novos entendimentos sobre a LRF.

Como contribuições, ressalta-se as particularidades dos achados, nessa importante região do Nordeste, pois é relevante disseminar os benefícios do conhecimento da LRF por parte dos vereadores, pois essa legislação aborda muitos pontos cruciais que merecem atenção especial por parte desses.

Como sugestão para trabalhos futuros, propõe-se: realizar o mesmo estudo em outros polos de desenvolvimentos, a fim de permitir comparações; investigar as dificuldades encontradas pelas câmaras no sentido de oferecer qualificações aos vereadores e analisar o entendimento da LRF em outros segmentos do setor público.

\section{REFERÊNCIAS}

Albanez, O. (2011). A Lei 4.320: anotada, revista e atualizada. (8. ed). Ribeirão Preto: Editora IBRAP.

Bastos, C. R. (1992).Curso de Direito Financeiro e de Direito Tributário. (2. ed). São Paulo: Saraiva.

Brasil. (2017). Constituição da República Federativa do Brasil de 1988. Brasília: Senado Federal, Subsecretaria de Edições Técnicas, 1988. Disponível em www.planalto.gov.br/ccivil_03/constituicao/constituicao.htm.

Brasil. (2017). Lei Complementar n. 113, de 19 de setembro de 2001, e regulamentada pelo Decreto $\mathrm{n}^{\circ} 4.366$, de 9 de setembro de 2002. A Região Administrativa Integrada de Desenvo/vimento do Polo Petrolina/PE e Juazeiro/BA.

Brasil. (2000). LRF - Lei Complementar n. 101, de 4 de maio de 2000. Estabelece normas de finanças públicas voltadas para a responsabilidade na gestão fiscal e dá outras providências. Diario Oficial da União, Brasilia.

Controladoria Geral da União. (2017). O vereador e a fiscalização dos recursos públicos municipais. Brasília CGU, Disponível em www.cgu.gov.br/cartilhavereadores.

Correio, M. N. O. P. (2019). Práticas de Governança Pública Adotadas pela Administração Pública Federal Brasileira. Administração Pública e Gestão Social, 11(2), 215-231.

Diniz, J. A., \& Santos, L. C. (2019). Sistema de Custo na Administração Pública: Uma Análise da Percepção de Prefeitos e Assessores Contábeis. Contexto - Revista do Programa de Pós-Graduação em Controladoria e Contabilidade da UFRGS, 19(41), 43-59. 
Figueiredo, D. S. de., \& Mello, J. C. C. B. S. de. (2009). Índice híbrido de eficácia e eficiência para lojas de varejo. Gestão \& Produção, 16(2), 286-300.

Figueiredo, C. M., \& Nobrega, M. (2005). Lei de Responsabilidade Fiscal. Série Impetus: Provas e Concursos. Rio de Janeiro: Elsevier.

Fontelles, M. J., Silva, M. G., Ferreira, S. H., \& Fortes, R. G. S. (2009). Metodologia da pesquisa científica: diretrizes para a elaboração de um protocolo de pesquisa. Revista Ciências e Cognição. Núcleo de Bioestatística Aplicado à pesquisa da Universidade da Amazônia - UNAMA.

Freitas, M. C. R., \& Pederneiras, M. M. (2020). Qualificação Profissional na Administração Pública: Análise da Percepção dos Técnicos Administrativos do CFP/UFCG. Revista de Carreiras e Pessoas, 10(1), 149-166.

Guimarães, P. S., \& Carvalho, C. R. R. (2020). Saneamento Básico Goiano: Uma Proposta de Intervenção Regulatória para o Aumento da Eficiência e Eficácia dos Serviços Oferecidos à População. Gestão \& Regionalidade, 36(108), 50-72.

Lima, D. V., \& Castro, R. G. (2000). Contabilidade Pública. (46. ed). São Paulo: Atlas.

Lopes, F. D. (2019). Criticism to the Transposition of Tools from Private Administration to Public Administration: A Debate on Modernizing Public Administration in Brazil. Revista de Administração da UFSM, 12(5), 841-856.

Lima, L. A. (2016). Análise e Evidenciação de Lei de Responsabilidade Fiscal em Municípios Pequenos. (Tese de Mestrado), São Paulo, Faculdade Campo Limpo Paulista - FACCAMP.

Matias-Perreira, J. (2007). Manual de metodologia da pesquisa científica. São Paulo: Atlas.

May, T. (2004). Pesquisa social: questões, métodos e processos. Porto Alegre: Artmed.

Meirelles, H. L. (2003). Direito Administrativo Brasileiro. (28. ed). São Paulo: Malheiros.

Nascimento, Edson Ronaldo. (2006). Gestão Pública. São Paulo: Saraiva.

Nascimento, S. (2014). Finanças Públicas. Teoria e mais 200 questões comentadas. (1. ed). Rio de Janeiro: Elsevier.

Naveira, R. B. (1998). Caos e complexidade nas organizações. Revista de Administração Pública, 32(5), 69-80.

Oliveira, I. G. S. (2015). Análise de correspondência aplicada a preposições sobre a eficiência e eficácia do processo de compras públicas a partir da percepção de diferentes atores envolvidos. Revista Ciências Administrativas, 21(1), 131-162. 
Pazzaglini Filho, M. (2006). Crimes de Responsabilidade Fiscal. São Paulo: Atlas.

Pereira, J. M. (1999). Finanças públicas: a política orçamentária no Brasil. São Paulo: Atlas.

Pinto, N. G. M., \& Coronel, D. A. (2017). Eficiência e eficácia na administração: proposição de modelos quantitativos. Revista Unemat de Contabilidade, 6(11), 107-130.

Pires, J. S. D. B., \& Motta, W. F. (2006). A evolução histórica do orçamento público e sua importância para a sociedade. Revista Enfoque Reflexão Contábil, 25 (2), 16-25.

Pires, V. A. (2011). Orçamento público: abordagem tecnopolítica. São Paulo: Cultura Acadêmica: Universidade Estadual Paulista.

Pradella, S. (2013). Gestão de Processos: uma metodologia redesenhada para a busca de maior eficiência e eficácia organizacional. Revista Gestão \& Tecnologia, 13(2), 94-121.

Rosa, M. B. (2011). Contabilidade do Setor Público. São Paulo: Atlas.

Silva, M. M., Amorim, F. A., \& Silva, V. L. (2004). Lei de Responsabilidade Fiscal para os municípios: uma abordagem prática. São Paulo: Atlas.

Silva, P. T. P. S. (2012). O orçamento público como ferramenta de análise de politicas públicas. Trabalho de Conclusão de Curso apresentado ao Instituto Serzedello Corrêa do Tribunal de Contas da União como parte da avaliação do Curso de Especialização em Orçamento Público. $151 f$. 